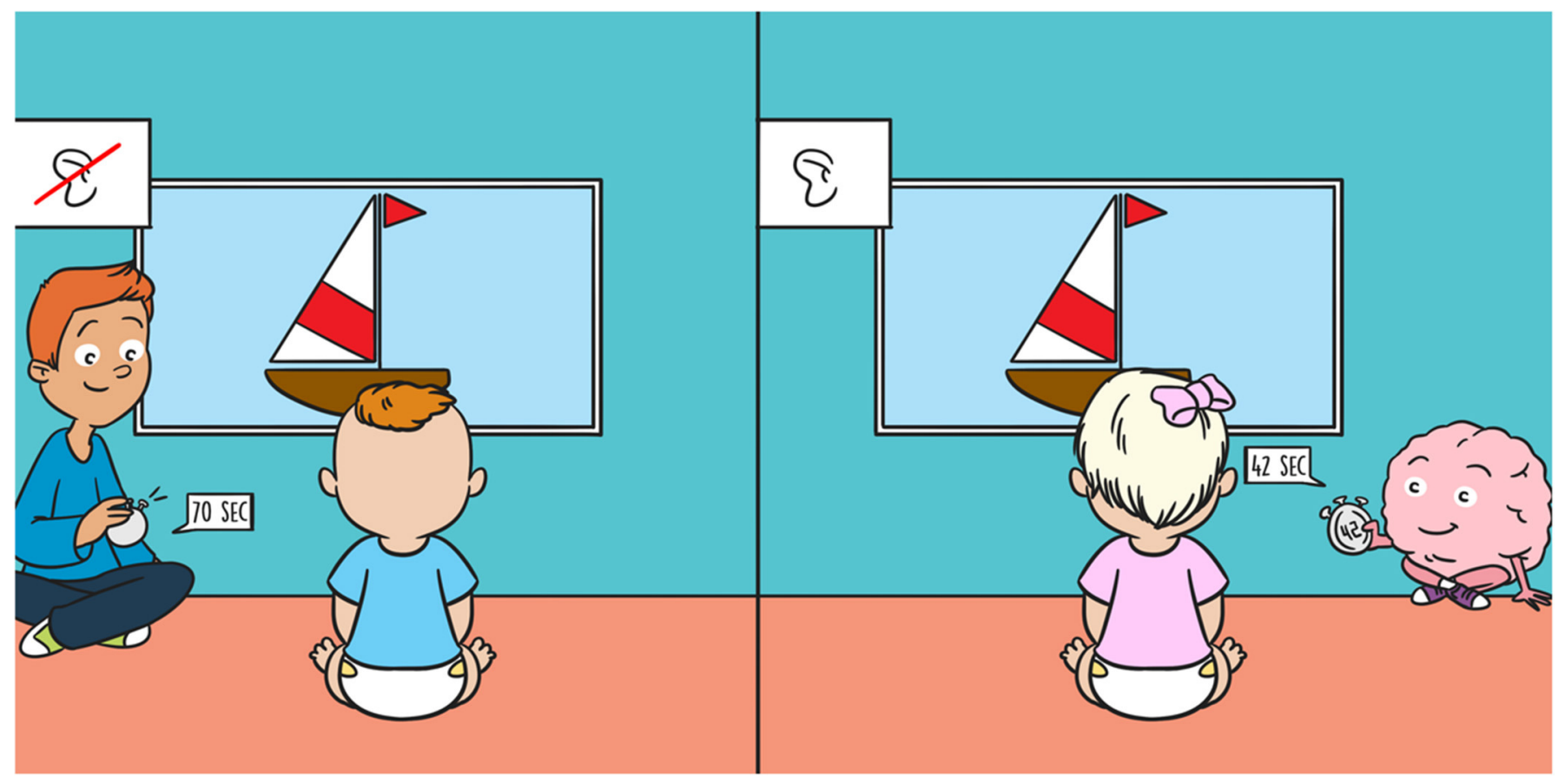

\title{
DOES BEING BORN DEAF AFFECT HOW WE SEE?
}

\section{Claire Monroy $^{1 *}$, Jonaye Freeman ${ }^{1}$ and Derek Houston ${ }^{1,2}$}

${ }^{1}$ Department of Otolaryngology-Head and Neck Surgery, The Ohio State University Wexner Medical Center, Columbus, OH, United States

${ }^{2}$ Nationwide Children's Hospital, Columbus, $\mathrm{OH}$, United States

YOUNG REVIEWER:

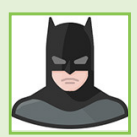

BATMAN

AGE: 14
Have you ever heard someone say that if you are born deaf, you have better vision to make up for it? People often think so, but is that actually true? We know that what babies hear, see, and touch determines how their brains develop. When you are growing, your brain is flexible. This means it changes depending on your experiences. Does this mean deafness changes how babies learn about things that they see? To explore this question, we tested two groups of babies to see how they processed visual information, meaning the objects that they saw. One group of babies was born deaf and the second group had normal hearing. We found that the deaf babies processed visual objects differently-even though the test had nothing to do with sound. This tells us that hearing loss in babies influences other senses, like vision. It also means that each sense affects how we learn about the world when we are still growing. 


\section{COCHLEAR}

\section{IMPLANT}

A small, surgically implanted device that gives people with hearing loss a sense of hearing. However, it does not make their hearing perfectly clear.

\section{COGNITION}

Mental processes like learning, attention, memory, language, and reasoning-abilities that have to do with thinking

\section{VISUAL}

\section{PROCESSING}

The way our brains learn new information from what we see with our eyes.

\section{HABITUATION}

When someone pays less attention to something after being exposed to it many times.

\section{INTRODUCTION}

Have you ever met someone who was deaf, or unable to hear well? There are many reasons that a person could be deaf or hard of hearing. Some illnesses or injuries can damage the ears and cause deafness, but sometimes deafness is congenital, meaning people are born that way.

If babies are born deaf or lose their hearing when they are little, it is difficult for them to learn how to talk. Sometimes, hearing loss can be an invisible condition. It can be very hard to tell when babies are deaf because they may look like nothing is wrong and act normally. A lot of times when babies are born deaf, their parents choose to have them get cochlear implants. A cochlear implant is a small device that is implanted into the baby's ear by a surgeon. Cochlear implants allow the deaf baby to hear sounds and learn how to speak.

Science shows that hearing loss also affects cognitive skills (like thinking, learning, memory, or attention). Babies with hearing loss learn differently than babies who can hear. This is not because they are not smart or cannot do things other babies can do. It is because the world is different for them than it is for someone who can hear.

In our study, we wanted to know if being born deaf affects visual processing. Visual processing is the way our brains understand what we see with our eyes. It is an important cognitive ability. By studying visual processing in deaf babies, we can learn more about how hearing loss affects how these babies learn and grow.

\section{WHAT DID WE DO?}

To study visual processing, we used something called a habituation test. Habituation is a simple form of learning that comes from being exposed to something many times. When babies become habituated to something (like a toy), they lose interest in it. This means that their brains have processed all the information about that toy.

For example, have you ever gotten a cool and exciting new toy? At first, you had a lot to learn about the toy. You probably played with it every day because it was so new and fun. But, after a while, maybe you began to get bored with it. That is because each time you played with it, your brain saved the information so there was less and less to learn about it. You became habituated to the toy, and you eventually lost interest and stopped playing with it.

In our study, we showed each baby two colorful objects on a TV screen, in a quiet room with no distractions (Figure 1). We showed them pictures-instead of cartoons or movies with sound-to make sure they were only using their vision to process the images. We 
Figure 1

Objects that we showed to the babies on a TV screen, to compare how long it would take deaf and hearing babies to habituate to the objects.

\section{BASELINE}

A starting point used for comparison. In our study, baseline means how long babies look at a new object the first time they see it.
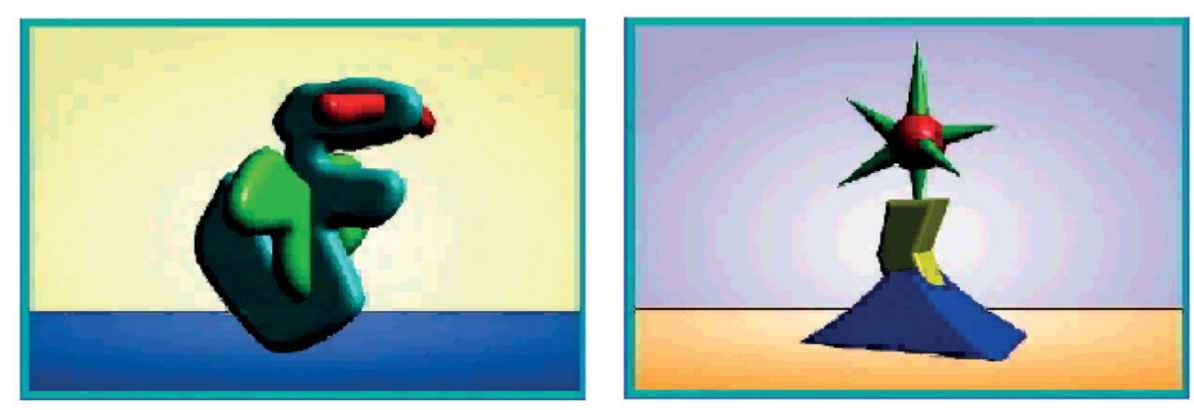

Figure 1

counted how many seconds it took them to look away from the objects. Looking away meant that they stopped paying attention. We showed the babies the objects on the screen repeatedly until they only looked at the objects for half the amount of time compared to the first time they were shown the objects. This meant that they lost interest and became habituated to the pictures. To compare deaf and hearing babies, we measured how long it took each group overall to habituate. Our hypothesis was that deaf and hearing babies would habituate to the toys at different times, because we believed that the two groups process visual information differently.

\section{WHAT DID WE FIND?}

As we thought, the deaf and hearing babies did behave differently in our experiment. The deaf babies took longer to habituate to the pictures of colorful toys. On average, they looked at the toys for about 70 total seconds during the test. The hearing babies looked at the toys for about 42 total seconds (Figure 2). We think this means the deaf babies took longer to process what they were seeing than the hearing babies.

You might be thinking-wait, what if the deaf babies are just more interested in the objects? To check this, we compared their baseline looking times during the very first trial. Baseline means how long they looked at the toys the very first time they saw them. It is kind of like their starting point. If deaf babies had a longer baseline, it could mean they were just more curious about the objects. However, both deaf and hearing babies had a similar baseline, meaning the first time they looked the toys, both groups of babies looked for about the same amount of time. The only difference was that the deaf babies took longer to lose interest in the objects after they were shown the objects multiple times.

\section{WHAT DOES THIS MEAN?}

Why did the deaf babies show slower habituation than the hearing babies? There are a few possible reasons. First, it could be that the deaf babies paid more attention because they were learning more 
Figure 2

The two stopwatches illustrate that, in our experiment, the deaf babies (left) took longer to lose interest in the objects pictured on the screen than the hearing babies did. This means that visual processing is different in deaf babies compared to hearing babies.

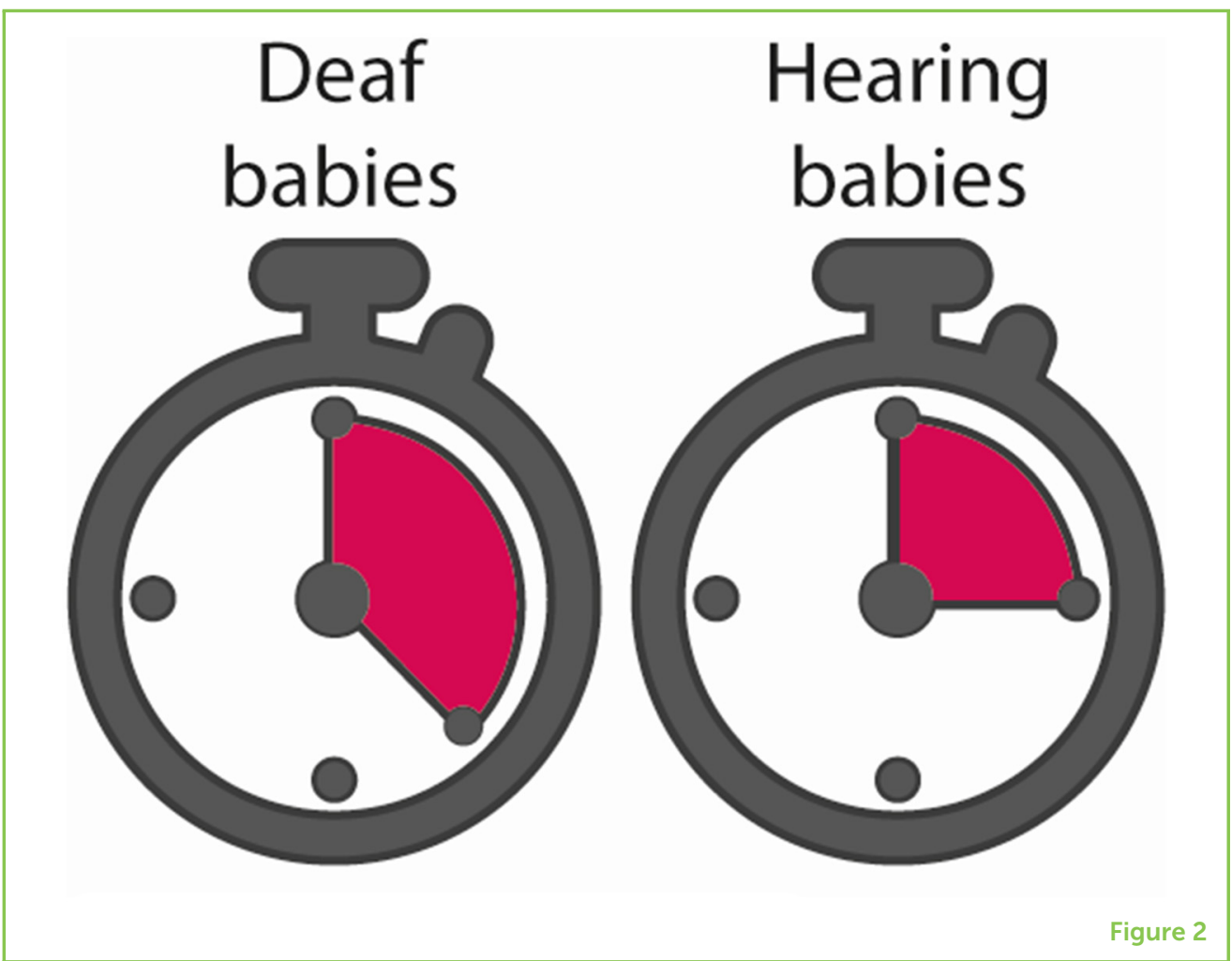

about the toys. They could have been noticing more details than the hearing babies. Or they might remember more about the toys later. Some scientists believe that deaf children need to rely on vision more heavily, since they cannot hear things around them [1]. This reliance on vision could change how their visual processing develops.

Another possible reason that deaf babies might have habituated more slowly is that their brain development could be a little less efficient. This might be because they were not able to hear sounds from birth. Some scientists think that hearing sounds is important for our brains to develop certain cognitive skills [2]. They think this could be why some deaf children struggle more with things like memory and attention.

A third possible reason for the slower habituation seen in our experiment could be that the deaf babies did not get to hear any language from birth. Deaf babies do not get to start learning language until later than hearing babies, and learning language is harder for them [3]. Language has a huge influence on our brain development. So, if we do not get to hear language as babies, this might have a negative effect on how we learn and grow. Remember how we talked about cochlear implants earlier? This is one reason why many parents want their babies to get cochlear implants. Cochlear implants allow the babies to start hearing sounds and learning spoken language. Other families help their babies to learn language by using sign language early in the babies' development. 


\section{CONCLUSION}

So, now we know there are differences in the way deaf and hearing babies use their vision. Now we need to do lots more work to understand why! Our study shows that deafness affects important cognitive abilities in babies - not just the cognitive abilities involved in hearing sounds. It also shows how the brain is connected with the senses in complex and interesting ways. When one sense is missing or impaired, this affects how we think, learn, and communicate. In the future, we plan to do more research to learn about the unique and special ways that deaf babies and children see the world.

\section{ORIGINAL SOURCE ARTICLE}

Monroy, C., Shafto, C., Castellanos, I., Bergeson, T., and Houston, D. 2019. Visual habituation in deaf and hearing infants. PLOS ONE 14: e0209265. doi: 10.1371/journal.pone.0209265

\section{REFERENCES}

1. Smith, L. B., Quittner, A. L., Osberger, M. J., and Miyamoto, R. 1998. Audition and visual attention: the developmental trajectory in deaf and hearing populations. Dev. Psychol. 34:840-50. doi: 10.1037/0012-1649.34.5.840

2. Conway, C., Pisoni, D. B., and Kronenberger, W. G. 2009. The importance of sound for cognitive sequencing abilities: the auditory scaffolding hypothesis. Curr. Dir. Psychol. Sci. 18:275-9. doi: 10.1111/j.1467-8721.2009.01651.x

3. Hall, M. L., Eigsti, I. M., Bortfeld, H., and Lillo-Martin, D. 2017. Auditory access, language access, and implicit sequence learning in deaf children. Dev. Sci. 21:e12575. doi: 10.1111/desc.12575

SUBMITTED: 13 February 2020; ACCEPTED: 25 May 2020; PUBLISHED ONLINE: 25 June 2020.

EDITED BY: Eilidh Cage, University of Stirling, United Kingdom

CITATION: Monroy C, Freeman J and Houston D (2020) Does Being Born Deaf Affect How We See? Front. Young Minds 8:82. doi: 10.3389/frym.2020.00082

CONFLICT OF INTEREST: The authors declare that the research was conducted in the absence of any commercial or financial relationships that could be construed as a potential conflict of interest.

COPYRIGHT @ 2020 Monroy, Freeman and Houston. This is an open-access article distributed under the terms of the Creative Commons Attribution License (CC BY). The use, distribution or reproduction in other forums is permitted, provided the original author(s) and the copyright owner(s) are credited and that the original publication in this journal is cited, in accordance with accepted academic practice. 


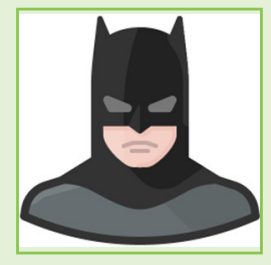

No use, distribution or reproduction is permitted which does not comply with these terms.

\section{YOUNG REVIEWER}

\section{BATMAN, AGE: 14}

Batman is very much interested in astronomy and biology. He is a very good in painting and loves animals.
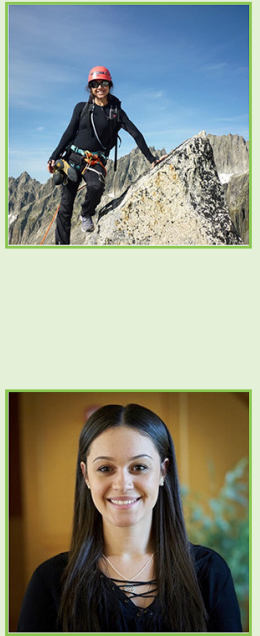

\section{AUTHORS}

\section{CLAIRE MONROY}

I am a post-doctoral fellow in the Department of Otolaryngology at The Ohio State University. I love science because I love learning new things all the time. My research is about infants' cognitive development during parent-infant interactions, and whether these are affected by hearing loss. In my free time, I love to rock climb. I also love mountains, cooking, and spending time with my loved ones. *claire.monroy@osumc.edu

\section{JONAYE FREEMAN}

I am a fourth-year undergraduate student at The Ohio State University, where I study biology and psychology. I like science because it is constantly changing, and new discoveries are made every day. When I graduate, I want to go to medical school so that I can become a doctor. In my spare time, I enjoy traveling, cooking, and spending time with my family and friends.

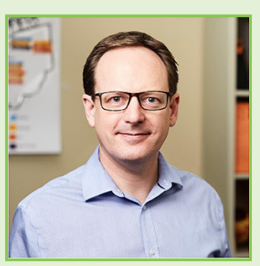

\section{DEREK HOUSTON}

I am a Cognitive Psychologist and Associate Professor of Otolaryngology at The Ohio State University. In 2000, I constructed the world's first laboratory to assess speech perception in infants who receive cochlear implants. I study language-related, cognitive, and social skills of young children with and without hearing loss. 